03,19

\title{
Математическое моделирование процесса выращивания монокристалла CdTe методом Обреимова-Шубникова
}

\author{
() М.Д. Павлюк ${ }^{1}$, Е.А. Суханова ${ }^{2}$, М.П. Зыкова ${ }^{2}$, И.С. Волчков ${ }^{1}$, В.М. Каневский \\ И.А. Субботин ${ }^{3}$, К.М. Подурец ${ }^{3}$, Б.Ф. Павлюк ${ }^{4}$ Ю.М. Иванов ${ }^{5}$ \\ ${ }^{1}$ ИК РАН, ФНИЦ „Кристаллография и фоотоника“ РАН, \\ Москва, Россия \\ ${ }^{2}$ Российский химико-технологический университет им. Д.И. Менделеева, \\ Москва, Россия \\ ${ }^{3}$ Национальный исследовательский центр „Курчатовский институт“, \\ Москва, Россия \\ ${ }^{4}$ ФГУП Всероссийский научно-исследовательский институт авиационных материалов, \\ Москва, Россия \\ ${ }^{5}$ Институт металлургии и материаловедения им. А.А. Байкова РАН, \\ Москва, Россия \\ E-mail: zenkova@crys.ras.ru
}

Поступила в Редакцию 16 июля 2019 г.

В окончательной редакции 16 июля 2019 г.

Принята к публикации 25 июля 2019 г.

Впервые выполнено моделирование ростового процесса кристалла СdТе модифицированным методом Обреимова-Шубникова с применением техники самозатравления от начальной температуры охлаждения $\left(1100^{\circ} \mathrm{C}\right)$ до момента выхода на режим стационарного роста. Рассчитано движение фронта кристаллизации в процессе роста кристалла. Результаты подтверждены методом рентгеновской топографии с использованием синхротронного излучения.

Ключевые слова: CdTe, фронт кристаллизации, термоконвективные потоки.

DOI: $10.21883 /$ FTT.2020.01.48722.24ks

\section{1. Введение}

Высококачественные кристаллы CdTe и твердые растворы на его основе активно используются при производстве различного рода приборов, широко применяемых в медицине, науке и промышленности. Поскольку потребность в кристаллах CdTe непрерывно растет, то одновременно растет и потребность в высококачественных кристаллах большого диаметра, так как это позволяет резко увеличить производительность процесса, повысить выход монокристаллического материала и снизить его стоимость. Наиболее распространенным способом выращивания кристаллов CdTe является стандартный метод Бриджмена, с осуществлением кристаллизации в запаяных кварцевых ампулах. Именно этим методом в последние годы были получены высококачественные структурно совершенные детекторные кристаллы с высоким временем жизни неосновных носителей заряда, доходящим до $11 \mu \mathrm{s}$ [1]. Однако серьезным недостатком метода Бриджмена является невысокий выход монокристалла, в лучшем случае 50\%. Основным препятствием выхода монокристалла являются трудности применения монокристаллической затравки, обусловленные применением малых осевых градиентов температуры и связанной с ними высокой вероятностью ее расплавления. Повышение осевого градиента температуры неблагоприятно влияет на структурные характеристики выращенного кристалла и является нежелательным.

Выбранный технологический процесс выращивания кристаллов CdTe основан на модифицированном методе Обреимова-Шубникова [2-4].

Данный метод имеет следующие преимущества по сравнению с методом Бриджмена:

- благодаря отсутствию механизма перемещения ампулы не вносятся дополнительных тепловых возмущений при зародышеобразовании и росте кристаллов;

- отсутствие перемещения ампулы приводит к преимущественному отводу тепла вдоль оси ампулы, обеспечивая необходимую форму фронта кристаллизации (в методе Бриджмена перемещение ампулы в холодную зону увеличивает вероятность отвода тепла в радиальном направлении, что приводит к паразитирующему зародышеобразованию на стенках ампулы);

- применение техники самозатравления с большой вероятностью приводит к получению полностью монокристаллических слитков, не требуя при этом использования затравочных монокристаллов, что удешевляет и упрощает процесс выращивания кристаллов CdTe.

Низкая теплопроводность твердого СdTе создает существенную проблему поддержания баланса теплового потока на поверхности раздела и диктует использование малой скорости роста и относительно больших температурных градиентов для выращивания крупных мо- 

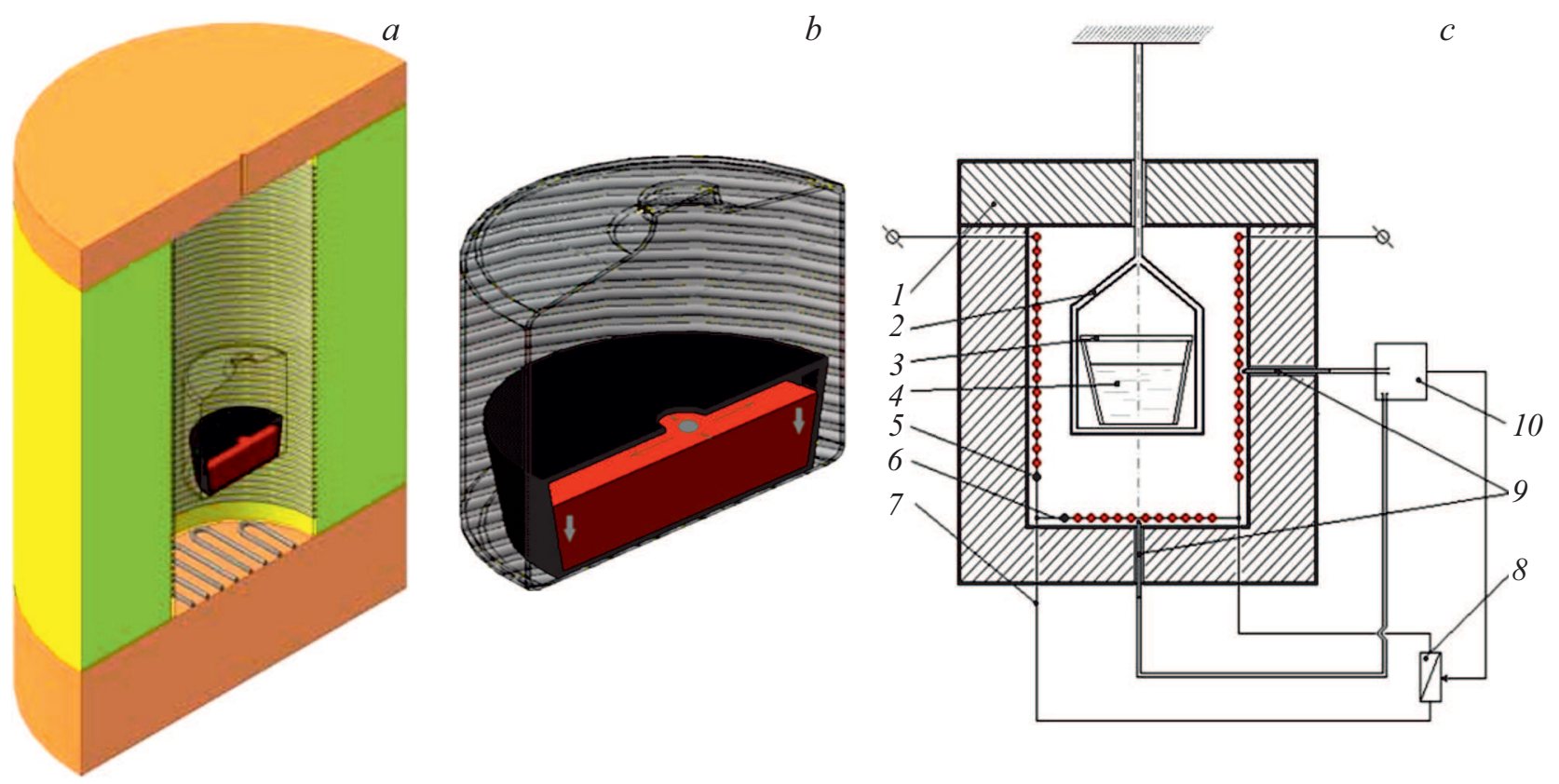

Рис. 1. Ростовая установка: a) 3D модель ростовой установки (в разрезе); b) схематическое изображение зарождение кристалла, его разрастание и последующий рост; с) схема печи: 1 - корпус печи, 2 - кварцевая ампула, 3 - ростовой тигель с крышкой, 4 - расплав, 5 - нагреватель стенки печи (спираль), 6 - нагреватель днища печи (змеевик), 7 - электрическая шунтирующая линия, 8 - переключатель, 9 - термопары, 10 - управляющее устройство.

нокристаллов. Описание теплопереноса в реальных системах выращивания кристаллов - сложная проблема, которая принимает во внимание все способы теплопереноса (кондуктивный, конвективный и радиационный) в расплаве и твердом теле, ростовом тигле и печи. Кинетика роста весьма интересна с точки зрения совершенствования технологии выращивания монокристаллов для понимания процессов образования оптических и структурных дефектов кристалла в течение ростового процесса. Непосредственное исследование кинетики в процессе выращивания кристаллов CdTe весьма затруднительно. Так как растущий кристалл хорошо экранирован, фронт кристаллизации (ФК) находится в расплаве и его визуализация невозможна.

Недостаток выращивания методами направленной кристаллизации расплавов - термоконвективные потоки, возникающие из-за негативного влияния неравномерного распределения температуры по объему тигля. Это приводит к неравномерному распределению концентрации компонентов по объему расплава, а также к флуктуациям температуры и состава в области фронта кристаллизации. Теоретические исследования влияния возникающих в расплаве градиентов температуры и концентрации на морфологию фронта кристаллизации показали важность равномерности их величин вдоль всей поверхности фронта.

В настоящей работе представлены результаты численного моделирования на основе решения системы нестационарных двумерных уравнений Навье-Стокса для несжимаемой жидкости в приближении Буссинеска, уравнений непрерывности, переноса тепла и теплопроводности процесса выращивания монокристалла CdTe диаметром $100 \mathrm{~mm}$ методом Обреимова-Шубникова. Задача решалась с использованием программного обеспечения ANSYS FLUENT 14.5

\section{2. Постановка задачи и метод решения}

\section{1. Модель ростовой установки}

Для моделирования процесса выращивания монокристалла CdTe диаметром $100 \mathrm{~mm}$ модифицированным методом Обреимова-Шубникова с использованием техники самозатравления в реальной кристаллизационной установке (печь фирмы „Кантал“) мы проектируем установку роста, показанную на рис. 1.

Учитывая, что CdTe характеризуется очень малой величиной критического сдвигового напряжения [5], применение малых температурных градиентов является существенным фактором, предотвращающим генерацию большого числа дислокаций на стадии роста кристалла. Для расчета были взяты следующие температурные градиенты: осевой - 2-3 grad/cm и радиальный $0.2-0.4 \mathrm{grad} / \mathrm{cm}$. В реальном ростовом процессе загруженная печь выдерживалась $10 \mathrm{~h}$ при показаниях нижней и боковой термопар $1100^{\circ} \mathrm{C}$. По истечении этого времени проводилось охлаждение со скоростью остывания $0.5^{\circ} \mathrm{C} / \mathrm{h}$, до показания нижней термопары 
Материалы и их физические свойства, используемые при моделировании

\begin{tabular}{|c|c|c|}
\hline Название & Детали & Свойства \\
\hline Фибротал & $\begin{array}{l}\text { Стенка печи } \\
\text { Дно печи } \\
\text { Крышка печи }\end{array}$ & $\begin{array}{l}\text { Плотность } \rho\left(\mathrm{kg} / \mathrm{m}^{3}\right)-200 \\
\text { Теплоемкость } C_{p}(\mathrm{~J} / \mathrm{kg} \mathrm{K})-1010 \\
\text { Теплопроводность } \lambda(\mathrm{W} / \mathrm{m} \mathrm{K})-0.28 \\
\text { Коэффициент теплового излучения } e(1 / \mathrm{m})-0.4\end{array}$ \\
\hline Фехраль & $\begin{array}{l}\text { Нагреватель стенки } \\
\text { печи (спираль) } \\
\text { Нагреватель дна } \\
\text { печи (спираль) }\end{array}$ & $\begin{array}{l}\text { Плотность } \rho\left(\mathrm{kg} / \mathrm{m}^{3}\right)-7100 \\
\text { Теплоемкость } C_{p}(\mathrm{~J} / \mathrm{kg} \mathrm{K})-480 \\
\text { Теплопроводность } \lambda(\mathrm{W} / \mathrm{m} \mathrm{K})-13.5 \\
\text { Коэффициент теплового излучения } e(1 / \mathrm{m})-0.7\end{array}$ \\
\hline Кварц $\mathrm{SiO}_{2}$ & $\begin{array}{l}\text { Кварцевая труба } \\
\text { Кварцевая ампула }\end{array}$ & $\begin{array}{l}\text { Плотность } \rho\left(\mathrm{kg} / \mathrm{m}^{3}\right)-2201 \\
\text { Теплоемкость } C_{p}(\mathrm{~J} / \mathrm{kg} \mathrm{K})-1052 \\
\text { Теплопроводность } \lambda(\mathrm{W} / \mathrm{m} \mathrm{K})-1.38 \\
\text { Коэффициент теплового излучения } e(1 / \mathrm{m})-0.5 \\
\text { Коэффициент преломления } n-1.4\end{array}$ \\
\hline $\begin{array}{l}\text { Стеклоуглерод } \\
\text { (графит) }\end{array}$ & Тигель с крышкой & $\begin{array}{l}\text { Плотность } \rho\left(\mathrm{kg} / \mathrm{m}^{3}\right)-1780 \\
\text { Теплоемкость } C_{p}(\mathrm{~J} / \mathrm{kg} \mathrm{K})-1900 \\
\text { Теплопроводность } \lambda(\mathrm{W} / \mathrm{m} \mathrm{K})-37 \\
\text { Коэффициент теплового излучения } e(1 / \mathrm{m})-0.5\end{array}$ \\
\hline $\begin{array}{c}\text { Теллурид } \\
\text { кадмия CdTe }\end{array}$ & Расплав & $\begin{array}{l}\text { Плотность } \rho\left(\mathrm{kg} / \mathrm{m}^{3}\right)-5680 \\
\text { Теплоемкость } C_{p}(\mathrm{~J} / \mathrm{kg} \mathrm{K})-187 \\
\text { Теплопроводность } \lambda(\mathrm{W} / \mathrm{m} \mathrm{K})-3 \\
\text { Коэффициент теплового излучения } e(1 / \mathrm{m})-1 \\
\text { Коэффициент теплового расширения } \beta(1 / \mathrm{K})-1.87 \cdot 10^{-4} \\
\text { Динамическая вязкость }(\mathrm{N} / \mathrm{m} \mathrm{s})-2.5 \cdot 10^{-3} \\
\text { Температура плавления } T_{m}(\mathrm{~K})-1373 \\
\text { Теплота плавления } H_{m}(\mathrm{~kJ} / \mathrm{kg})-209.2\end{array}$ \\
\hline Пар кадмия Cd & $\begin{array}{l}\text { Атмосфера } \\
\text { кварцевой ампулы }\end{array}$ & $\begin{array}{l}\text { Плотность } \rho\left(\mathrm{kg} / \mathrm{m}^{3}\right)-0.33 \\
\text { Теплоемкость } C_{p}(\mathrm{~J} / \mathrm{kg} \mathrm{K})-106.43 \\
\text { Теплопроводность } \lambda(\mathrm{W} / \mathrm{m} \mathrm{K})-0.0242 \\
\text { Коэффициент теплового излучения } e(1 / \mathrm{m})-0 \\
\text { Коэффициент теплового расширения } \beta(1 / \mathrm{K})-4.57 \cdot 10^{-4} \\
\text { Динамическая вязкость }(\mathrm{N} / \mathrm{m} \mathrm{s})-1.78 \cdot 10^{-5}\end{array}$ \\
\hline
\end{tabular}

$1090^{\circ} \mathrm{C}$, а боковой $-1092^{\circ} \mathrm{C}$. С этого момента нижний нагреватель выключается. Детально метод описан в [3].

Все свойства используемых материалов принимались постоянными и использовались их значения при температуре $1100^{\circ} \mathrm{C}$ (см. таблицу).

\section{2. Численное моделирование}

Использовалась двумерная модель в осесимметричном приближении.

Были заданы граничные условия для температуры и скорости потоков. На стенках использовалось условие прилипания. На внешних стенках печи учитывался свободный конвективный теплообмен с окружающей средой, на стенках ампулы - температурный профиль. Для учета излучательного теплопереноса использовалась модель дискретных ординат. Стенки кварцевой ампулы считались абсолютно прозрачными для излучения; остальные стенки считались абсолютно непрозрачными.
Для моделирования процесса кристаллизации использовалась энтальпийная модель.

Сетка образована четырехугольными ячейками, с основным размером в области внутри ампулы 1 и $2 \mathrm{~mm}$ в печи. Сетка имела пограничные слои уменьшенных ячеек вдоль внутренних стенок ампулы и тигля. Общее количество ячеек сетки составило 56000.

\section{3. Результаты расчета и обсуждение}

Расчет проводился в три этапа. На первом этапе рассчитывали тепловой профиль шахты пустой печи (рис. 2). Шахта печи заполнена воздухом, для которого рассчитывается конвекция.

На рис. 2 видны весьма интенсивные термоконвективные потоки вдоль оси печи, возникающие за счет отвода тепла через центральное отверстие в крышке печи, причем за счет того, что крышка не обогревается, в верхней части печи термоконвективные потоки носят сложный характер. 


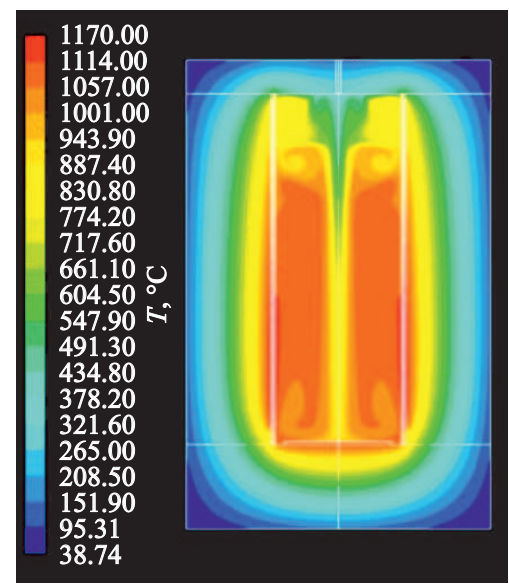

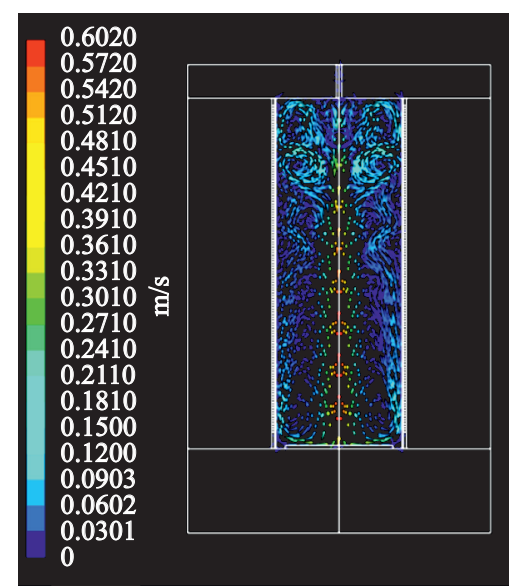

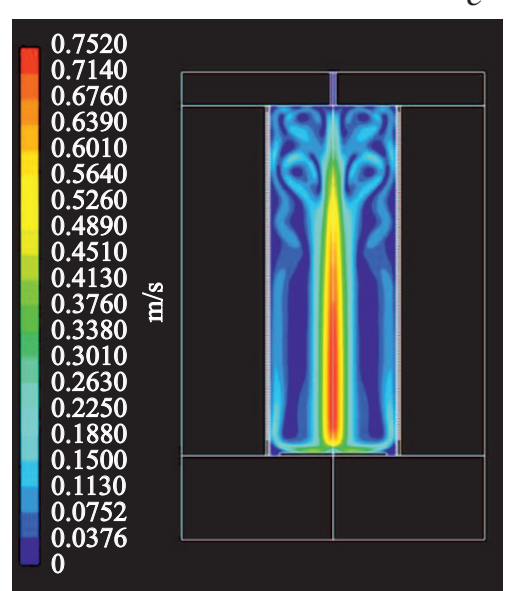

Рис. 2. Распределение температур $(a)$, векторов осредененных скоростей термоконвективных потоков $(b)$ и термоконвективных потоков $(c)$ в шахте печи в отсутствие ампулы с расплавом и тиглем.

$a$
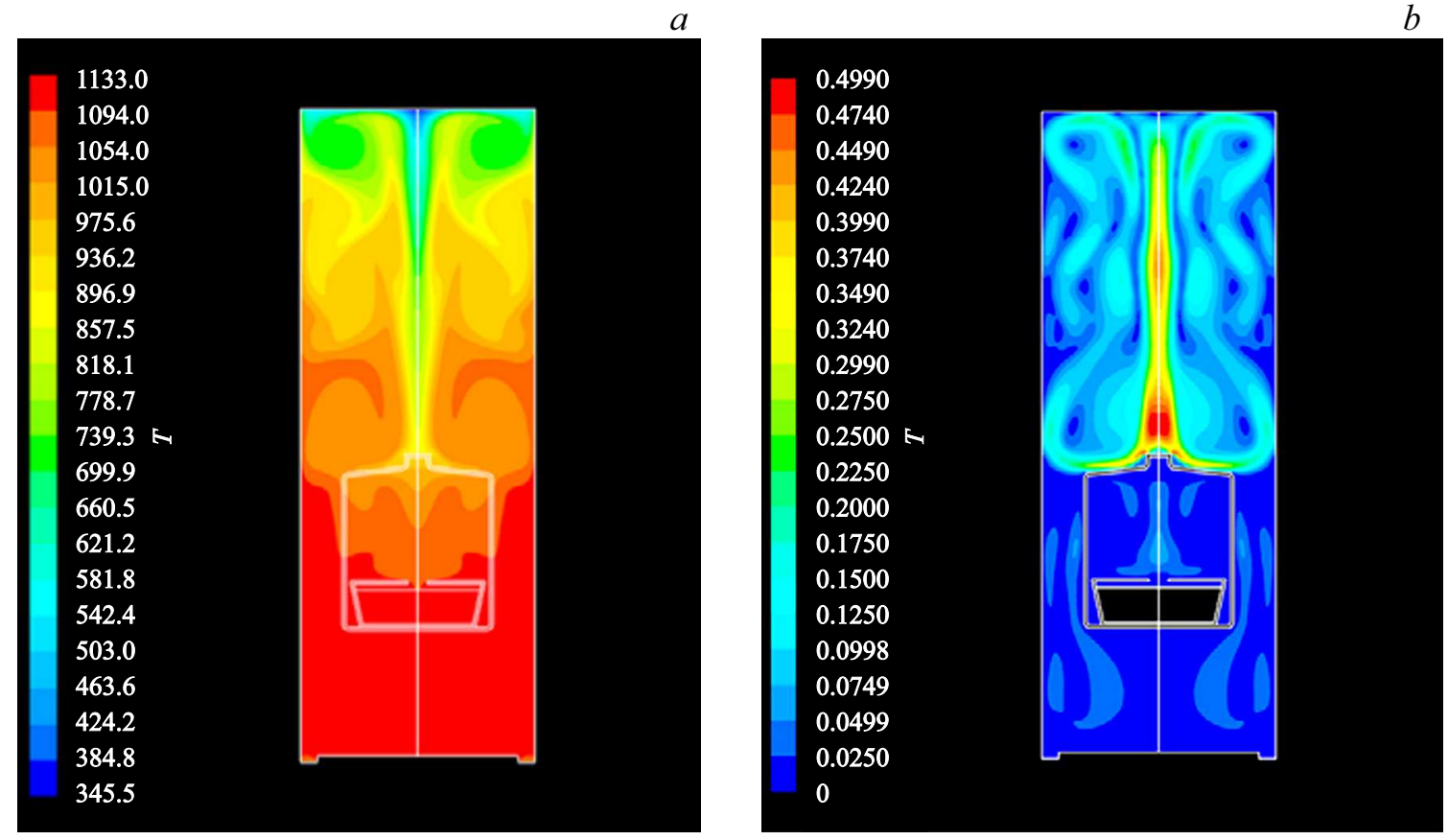

Рис. 3. Распределение температур $(a)$ и термоконвективных потоков $(b)$ во внутреннем пространстве печи с кварцевой ампулой и находящимся в ней тиглем с расплавом.

На втором этапе моделировались процесы во внутреннем пространстве печи с кварцевой ампулой и находящимся в ней тиглем с расплавом. Расплав на этой стадии предполагается твердым. Для внутреннего пространства ампулы (паровая фаза) и воздуха в шахте печи рассчитывалась термоконвекция. Теплообмен осуществлялся как за счет теплопроводности и конвекции, так и за счет переноса тепла излучением. Расчет проводился с учетом ранее найденного распределения температуры в печи.

На рис. 3 видно, что температура в тигле распределена равномерно. Введение ампулы в печь в нижней части печи приводит практически к равномерному распределе- нию термоконвективных потоков и низким их скоростям. В верхней части печи сохраняется сложный характер термоконвективных потоков.

На третьем этапе рассчитываются потоки в тигле с использованием тепловых условий, полученных в предыдущих расчетах. В расчете была учтена кристаллизация жидкого расплава с использованием энтальпийной модели.

Расчеты показали, что полностью кристаллизация слитка происходит за $22 \mathrm{~h} 20 \mathrm{~min}$ (точность $\pm 5 \mathrm{~min}$ ), что соответствует реальному ростовому процессу и нашему представлению о технике самозатравления. Следует 


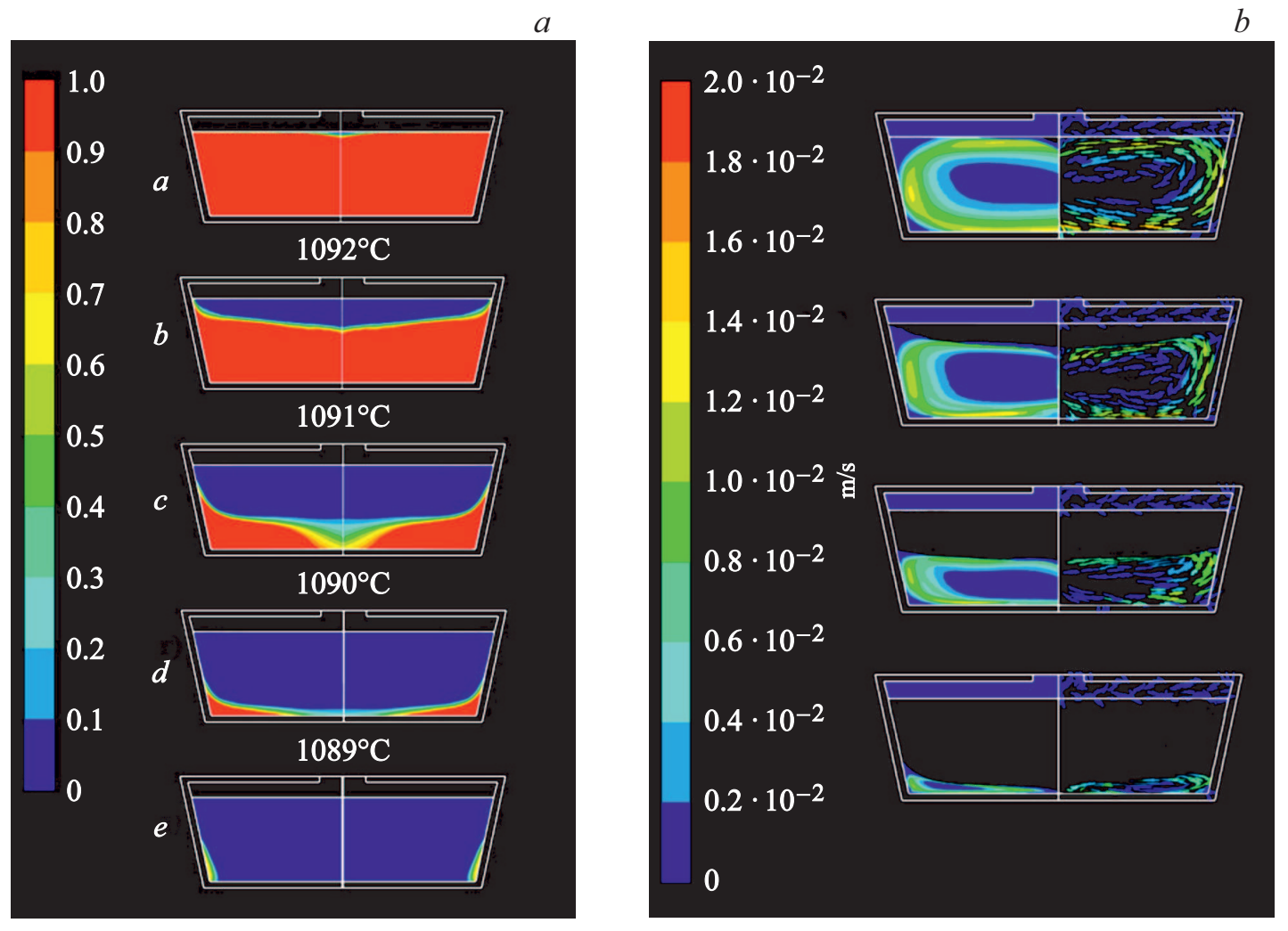

Рис. 4. $a-$ вид фронта кристаллизации кристалла от момента затравления до выхода на режим стационарного роста, $b-$ скорости термоконвективных потоков, справа векторные скорости $(V, \mathrm{~m} / \mathrm{s})$.

$a$

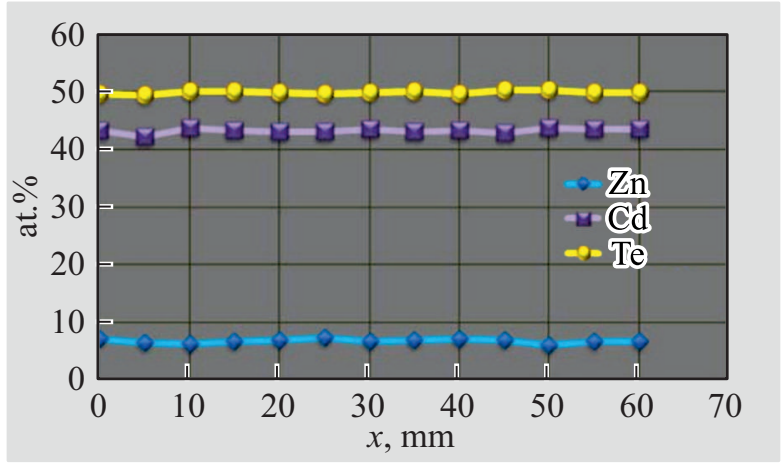

$b$

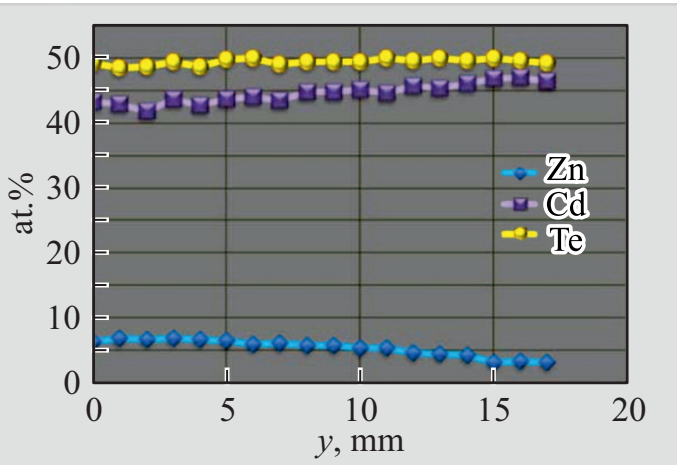

Pис. 5. Диаграмма распределения компонентов: $a$ - перпендикулярно оси роста слитка и $b$ - по высоте слитка в кристалле CdZnTe.

отметить, что в процессе охлаждения кристалла, наибольшая часть времени (а именно, $18 \mathrm{~h}$ ) отводится остыванию расплава, перегретого на $10^{\circ} \mathrm{C}$, до температуры плавления $1092^{\circ} \mathrm{C}$. Последующие $4 \mathrm{~h}$ соответствуют интервалу температур $1092-1089^{\circ} \mathrm{C}$ (рис. $\left.4, b-e\right)$. Показано, что разращивание кристалла произошло достаточно быстро в радиальном направлении, после чего процесс роста вышел на почти стационарный режим. В расплаве борются два типа конвекции: свободная (связанная с перепадом температуры в тигле) и вынужденная. Первая вместе с отводом тепла от фронта кристаллизации посредством излучения стремится прогнуть фронт в расплав, а вторая, наоборот, сделать его плоским. Под кристаллом образовался вихрь вынужденной конвекции, однако этой скорости было недостаточно для существенного изменения формы фронта кристаллизации.

На практике ФК можно определить в дефектных монокристаллах по декорированию этого фронта в нескольких местах кристалла микропузырьками, или использование рентгеновского микроанализа позволяет выявить распределение компонентов вдоль оси роста и диаметра слитка. Эти данные позволяют сравнивать полученные 


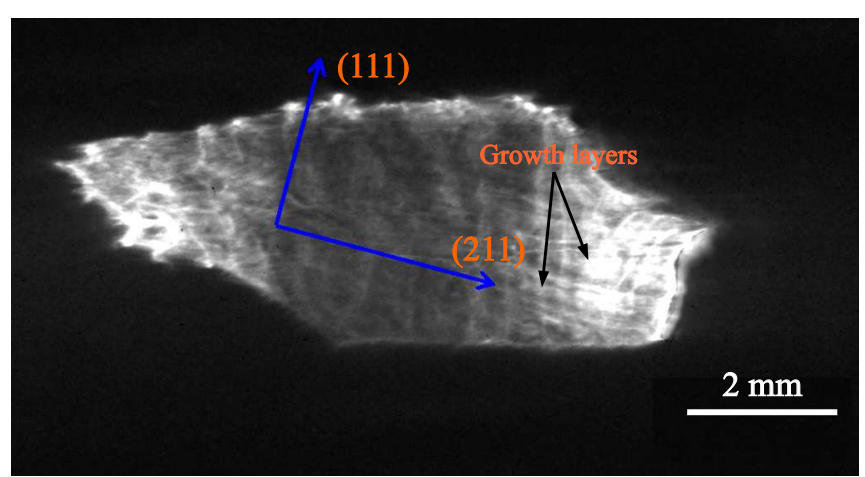

Рис. 6. Рентгеновская топография кристалла CdZnTe.

с помощью моделирования результаты с практическими данными.

Для сравнения с результатами моделирования был выращен кристалл $\mathrm{CdZnTe}$ с концентрацией Zn 7 at.\% (с теми же параметрами, которые были взяты при расчете). Использование рентгеновского микроанализа (Метод энергодисперсионной рентгеновской спектроскопии (англ. Energy-dispersive $X$-ray spectroscopy (EDS) на руском языке сокращенно ЭДС)) позволило выявить распределение компонентов вдоль и перпендикулярно оси роста слитка и установить высокую микрооднородность компонентов (рис. 5, $a$ и $b$ соответственно). Полученные данные о микрооднородности образцов, подтверждают отсутствие процессов распада твердых растворов. Распределение компонентов на представленных диаграммах свидетельствует о плоском фронте кристаллизации слитков.

Результаты расчета согласуются с результатами ростового эксперимента, оцененными по данным рентгеновского микроанализа, что подтверждает адекватность численной модели.

Для надежности полученных результатов были проведены дополнительные исследования, а именно, была проведена рентгеновская топография на синхротронном источнике. Исследования с использованием синхротронного излучения проводили на станции „Медиана“ Курчатовского источника синхротронного излучения. Изображения регистрировались с помощью двухкоординатного детектора на основе GdOS:Tb-экрана и CCD-матрицы размерностью $4008 \times 2672$ пикселей, размер пикселя составлял $8.9 \mu \mathrm{m}$. Для топографии на белом пучке кристалл устанавливали в симметричной геометрии с горизонтальной плоскостью дифракции, и отражение под брэгговским углом $q \approx 15^{\circ}$ регистрировали детектором, расположенным на расстоянии $30 \mathrm{~cm}$ от кристалла. Высота пучка составляла $5 \mathrm{~mm}$. Время регистрации одного изображения составляло $15 \mathrm{~s}$ (обычное время для слабопоглощающих кристаллов - $1 \mathrm{~s})$.

Ориентировка кристалла с естественным сколом (110) проводилась на рентгеновском дифрактометре Rigaku SmartLab (Токио, Япония) с использованием характе- ристического излучения меди. В состав дифрактометра входит пятиосевая система позиционирования образца с радиальным и азимутальным вращением, позволяющая легко вывести искомую плоскость в дифракционное положение. Результаты топографии, полученные с помощью синхротронного излучения, полностью подтверждают адекватность численной модели и полностью соответствуют данным рентгеновского микроанализа, как в осевом, так и в радиальном направлениях.

\section{4. Заключение}

В настоящей работе выполнено моделирование ростового процесса кристалла CdTe модифицированным методом Обреимова-Шубникова с применением техники самозатравления, с использованием программного обеспечения ANSYS FLUENT 14.5. Рассчитано, что межфазная граница на стадии разращивания кристалла слегка выпуклая, а при температуре $1090^{\circ} \mathrm{C}$ форма фронта кристаллизации становится плоской. Результаты расчета согласуются с результатами ростового эксперимента по данным рентгеновского микроанализа. А результаты топографии, полученные с помощью синхротронного излучения, полностью подтверждают адекватность численной модели.

\section{Финансирование работы}

Работа выполнена при поддержке Министерства науки и высшего образования в рамках выполнения работ по Государственному заданию ФНИЦ „Кристаллография и фотоника" РАН.

\section{Конфликт интересов}

Авторы заявляют, что у них нет конфликта интересов.

\section{Список литературы}

[1] M. Azoulay, A. Raizman, G. Gafni, M. Roth. J. Cryst. Growth. 101, 256 (1990)

[2] Yu.M. Ivanov. J. Cryst. Growth. 194, 509 (1998).

[3] Ю.М. Иванов, А.Н, Поляков, М.Д. Зенкова, В.М. Каневский. Установка для выращивания кристаллов / Патент на полезную модель RU 51030 U1 2006.

[4] M.D. Pavlyuk, V.M. Kanevsky, V.F. Dvoryankin, A.A. Kudryashov, A.G. Petrov, Yu.M. Ivanov. Nucl. Instrum. Methods Phys. Res. A 624, 482 (2010).

[5] Osamu Oda. Compound semiconductor bulk materials and characterizations. World Scientific Publishing Company, Singapore (2007). $556 \mathrm{p}$.

Редактор Е.Ю. Флегонтова 